WellBeing International

WBI Studies Repository

$1-1992$

\title{
Vocal Recognition in Mexican Free-Tailed Bats: Do Pups Recognize Mothers?
}

Jonathan Balcombe

Gary F. McCracken

University of Tennessee - Knoxville

Follow this and additional works at: https://www.wellbeingintlstudiesrepository.org/acwp_asie

Part of the Animal Studies Commons, Comparative Psychology Commons, and the Other Animal Sciences Commons

\section{Recommended Citation}

Balcombe, J.P., \& McCracken, G.F. (1992). Vocal recognition in Mexican free-tailed bats: do pups recognize mothers? Animal Behavior, 43(1), 79-87.

This material is brought to you for free and open access by WellBeing International. It has been accepted for inclusion by an authorized administrator of the WBI Studies Repository. For more information, please contact wbisr-info@wellbeingintl.org.

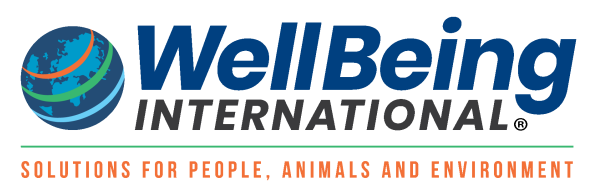




\title{
Vocal Recognition in Mexican Free-Tailed Bats: Do Pups Recognize Mothers?
}

\author{
Jonathan P. Balcombe \& Gary F. McCracken
}

Recommended Citation:

Balcombe, J.P., \& McCracken, G.F. (1992). Vocal recognition in Mexican free-tailed bats: do pups recognize mothers? Animal Behavior, 43(1), 79-87.

\begin{abstract}
Mother Mexican free-tailed bats, Tadarida brasiliensis mexicana, produce 'directive' calls while searching for pups inside cave maternity roosts. These calls consist of highly repetitive pulses of sound uttered in rapid sequence. Calls are sufficiently intense that they are perceptible above the substantial background noise within roosts at distances of at least $1 \mathrm{~m}$. Calls are stereotyped within individuals, and statistically discriminable between individuals. These characteristics are expected for vocalizations that function for mother-pup reunions, and are shared with directive calls described previously in other bats. Mother T. b. mexicana directive calls are statistically no less discriminable than are the isolation calls of pups. Playback experiments, using recordings made inside the cave colony, show that pups perceive directive calls and are strongly attracted to them.
\end{abstract}

\section{INTRODUCTION}

It is often essential for parents to recognize their offspring, but it also may be advantageous to both parties if offspring can recognize their parents. Recognition of parents by offspring could facilitate parent offspring reunions by stimulating young to approach the parent and/or to vocalize (Beecher 1981; Holmes 1990). This, in turn, should reduce the possibilities of misdirected parental care and aggressive reactions by adults toward solicitations from unfamiliar young (Beer 1970; Pierotti \& Murphy 1987). Recognition of parents by young has been documented for many birds (e.g. McArthur 1982; Beecher et al. 1985; Jones et al. 1987), and some mammals (e.g. Trillmich 1981; Rother \& Schmidt 1985).

A priori, we expect strong selection for reciprocal parent-offspring recognition in Mexican free-tailed bats, Tadarida brasiliensis mexicana. Maternal investment is high; during the 5week period from birth to weaning, each mother nurses her single pup several times daily with large quantities of extremely rich milk (Davis et al. 1962; Kunz, unpublished data). Furthermore, the roosting habits of $\mathrm{T}$. b. mexicana provide great potential for confusion 
among mothers and pups (McCracken \& Gustin, in press). Pups roost separately from mothers in creches that often number millions of individuals at densities in excess of 5000 per m2 (McCracken 1984; McCracken \& Gustin, in press). Pups are mobile on these creches from the first day after birth (Davis et al. 1962) and mix, apparently at random, over areas of several square metres (McCracken \& Gustin, in press).

Recent studies of reunion behaviour in captive T. b. mexicana have documented both olfactory (Gustin \& McCracken 1987) and acoustic recognition (Balcombe 1990) of pups by their mother. In-cave observations of mother-pup behavior using a night vision device and an infrared video system clearly indicate the use of both vocal and olfactory cues by adults searching for pups (McCracken \& Gustin, in press). These same observations also suggest reciprocal vocal and olfactory recognition of adults by pups. However, experiments on pup recognition of mothers have been equivocal for olfactory (cf. Loughry \& McCracken 1991) and acoustic (mother echolocation) cues (Balcombe 1990). In this paper we describe a specific vocalization used by mother T. b. Mexicana during reunion searches for their pups. The characteristics of this 'directive' call make it highly suitable for an individual recognition function. We also show, using playbacks of calls recorded inside a maternity colony and presented to pups, that pups perceive and are strongly attracted to these calls.

\section{METHODS}

\section{Study Sites and Dates}

We conducted this research at James River Cave, the site of a large maternity colony of $\mathrm{T}$. b. Mexicana in south-central Texas (Mason County). Audio recordings of reunions between pups and their presumed mothers were made inside the cave on nine nights between 14 June and 28 July 1989. Playback presentations of recorded calls were conducted between 4 and 11 July 1989 at a research base located $0.7 \mathrm{~km}$ from the cave. In the late 19S0s, it was estimated that James River Cave housed approximately 6 × $106 \mathrm{~T}$. b. mexicana (Davis et al. 1962). More recent estimates of the colony size are not available; however, it still contains an extremely large population.

\section{Audio and Video Recordings}

Efforts to obtain directive calls from captive mothers for playback presentation to captive pups were unsuccessful. Thus, we could not employ choice test experiments (e.g. Gustin \& McCracken 1987; Balcombe 1990) to test individual vocal recognition by pups. The reason for our failure to elicit directive calls from captive mothers is unknown, but may have resulted from our inability to simulate the atmospheric and acoustic conditions that exist in the large natural maternity colonies of T. b. mexicana. Recordings of the calls of mothers searching for pups inside the roost at James River Cave were made with a QMC model SM 1 microphone mounted on a tripod placed 1-1.5 m from pup creches on the cave wall. Calls were amplified with a QMC S200 bat detector, and recorded outside of the cave on a Racal Store 40 reel-to-reel tape recorder operated at $76 \mathrm{~cm} / \mathrm{s}$. The microphone was housed in a plastic calf milking bottle measuring $25 \times 10 \times 10 \mathrm{~cm}$, lined with cotton wool. This housing improved the microphone directionality and also protected it from the constant rail of guano and urine from bat roosting overhead. Incoming signals were monitored on a Tektronix 212 oscilloscope to avoid saturation (clipping) of the recorded calls. 
An additional set of in-cave audio recordings was made for use in playback experiments (see below). These recordings were of vocalizations in pup creches with and without the presence of calling mothers. We recorded a creche at about 2200 hours, after mothers had left the cave to forage. We then recorded the same creche again after 2330 hours, following the return of many mothers to the cave.

To identify individual bats making calls, simultaneous video recordings of the creche area were made using a JAI model XC-37 infrared (IR) sensitive video camera. Illumination was provided by two IR light-emitting diodes (Lightning Bug, CW Model TDOO, Special Services), mounted on the camera housing. Adult females are behaviourally indifferent to these IR lights (Mistry \& McCracken 1990). Using a 70-210 mm, f3.4 zoom lens, the area of the camera's view was adjusted to obtain about 300 pups on the surface of the cave wall, with the field of view centred on the area from which audio recordings were being made. Video recordings were monitored from outside the cave on a portable TV-monitor. We communicated via radio (Realistic TRC-211) to set up the camera and microphone. The person outside the cave watched the video monitor and gave instructions to the person inside the cave for adjusting camera angle, field of view, focus and the gain setting on the amplifier.

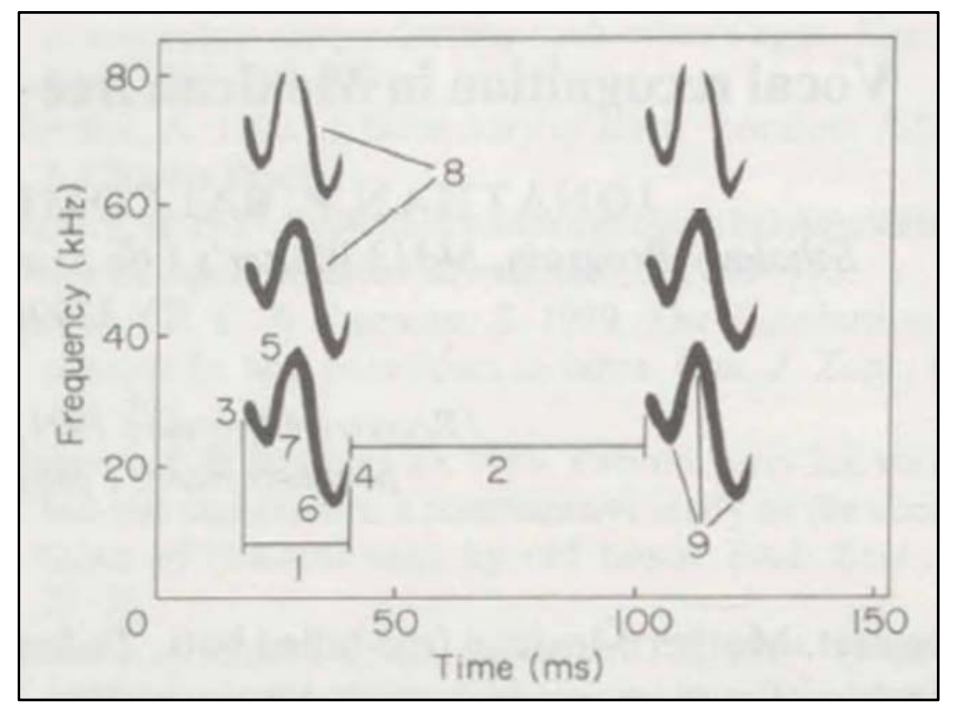

Figure 1. Schematic representation of two pulses from a directive call showing the nine parameters analysed: 1, pulse duration; 2, inter-pulse interval; 3, initial frequency of the fundamental; 4, final frequency of the fundamental; 5, maximum frequency of the fundamental; 6 , minimum frequency of the fundamental; 7 , frequency of maximum energy; 8 , number of harmonics; 9, number of inversions in the fundamental (i.e. number of consecutive modulations $=$ three for each pulse shown.

\section{Sound Analysis}

We analysed 100 adult directive calls (two each from 50 mother bats) with a MacSpeech Lab II sound analysis computer. Each directive call comprised several pulses of sound. Nine measurements (Fig. 1) were taken from each of three successive pulses in each call analysed (total $=300$ pulses analysed). We identified calls for analysis by playing recordings at slower speeds (38 or $19 \mathrm{~cm} / \mathrm{s}$ ) through a speaker (Technics EAS-JOTH400B leaf tweeter) and listening for directive calls. Only intense calls that were clearly detectable above 
background noise were analysed. Because the intensity of a recorded call can be strongly influenced by the proximity and orientation of the microphone toward the calling bat, call intensity was not one of the call features measured.

We also analysed the same nine measurements from 100 isolation calls from $50 \mathrm{~T}$. b. mexicana pups that were recorded in captivity between 1987 and 1989 (Balcombe 1990). We used these measurements to compare the discriminability of adult directive calls with that of pup isolation calls.

\section{Playbacks}

The playback equipment, experimental protocol and housing of bats in this study were identical to those in Balcombe (1990). Playbacks of recordings made in caves were presented to captive pups to test whether pups are attracted to mother directive calls. Each pup was presented with two recordings. From one speaker we played a recording of a pup creche made in the absence of mothers and containing few discernible (to us) directive calls; from the other speaker, we played a recording of the same creche with mothers present and containing many discernible directive calls. Three pairs of recordings, each made on separate creches on different nights, were used in these playbacks. The directive call stimuli contained an average ( \pm SE) of $145.7 \pm 23.2$ calls per min; the other stimuli contained an average of $32 \cdot 2 \pm 11.4$ calls per min.

We conducted playback experiments using 20 pups, tested individually, between 1800 and 2030 hours during three sessions: 4 July (six pups), 8 July (six pups), and II July (eight pups). The duration of each trial in this study was $8 \mathrm{~min}$, compared with 5 min in Balcombe (1990). As in the earlier studies, a pup was introduced into a circular wire-screen arena (38 $\mathrm{cm}$ diameter $\times 7.5 \mathrm{~cm}$ ) through a plastic tube, and was scored for the amount of time spent in contact with a cloth bat model placed in front of each of two speakers. The speakers were opposite one another on either side of the arena, facing inward towards its centre. All playbacks were blind, with an assistant assigning the stimuli to the left and right sides of the arena according to a coin toss. To avoid confounding pup responses to sound intensity, the gain knob on each amplifier was adjusted to equalize the sound pressure level from each speaker. Pup responses were scored at the time spent in contact with each model. Control 'playbacks', in which the tape recorder was operated with blank tape, have shown that bats respond to sounds from the speakers rather than to the cloth bat models (Balcombe 1990).

\section{Statistical Procedures}

A single directive call consists of pulses that occur in rapid succession (see below) and characteristics of any pulse may depend on the characteristics of the pulse or pulses that immediately prededed it. This within-call pulse dependency could bias the analysis towards the hypothesis of within-individual call stereotypy. To minimize this potential bias, we analysed three pulses from each of two separate calls from each bat, one call from the beginning and one from the end of a recorded sequence. We analysed mother directive calls using principal components analysis (PCA) and discriminant function analysis (DFA). We used principal components analysis to determine the amount of variance between calls that could be attributed to particular call measurements (SAS, PROC FACTOR; SAS Institute 
1989), and to reduce the information contained in the analysed calls to a two-dimensional, two-factor space (Afifi \& Clark 1984). We used discriminant function analysis to classify directive call pulses as to mother identity using PROC DISCRIM (SAS Institute 1989), which uses the pooled covariance matrix to calculate Mahalanobis distances. We used the 'crossvalidation' option (SAS Institute 1989), which classifies each observation in the data set using a discriminant function computed from the other observations in the data set, excluding the observation being classified (Afifi \& Clark 1984). We also used discriminant function analysis to compare our measures of discriminability of 100 mother directive calls with 100 pup isolation calls that were recorded in an earlier study (Balcombe 1990). Since the data were not normally distributed, non-parametric discriminant function analyses were employed (PROC DISCRIM, SAS Institute 1989), using the kernal method with uniform radius of $2 \cdot 5$ (Hand 1981).

Pup responses to playbacks were assessed using a difference score (D) for each pup; $D=T_{1}-T_{2}$, where $T_{1}$ is time spent in contact with the model in front of the speaker broadcasting the directive call stimulus, and $T_{2}$ is time in contact with the other model. The null hypothesis that the mean of the difference scores was equal to zero was tested with a one-tailed t-test (PROC TTEST; SAS Institute 1989).

\section{RESULTS}

\section{Characteristics of Directive Calls}

Directive calls of mother T. b. mexicana consisted of a burst of vocal pulses occurring in rapid succession (Fig. 2). The typical number of pulses in each call was between four and six, but ranged from 2 to 18 . Temporal and frequency characteristics of $T$. b. mexicana directive calls are summarized in Table 1.

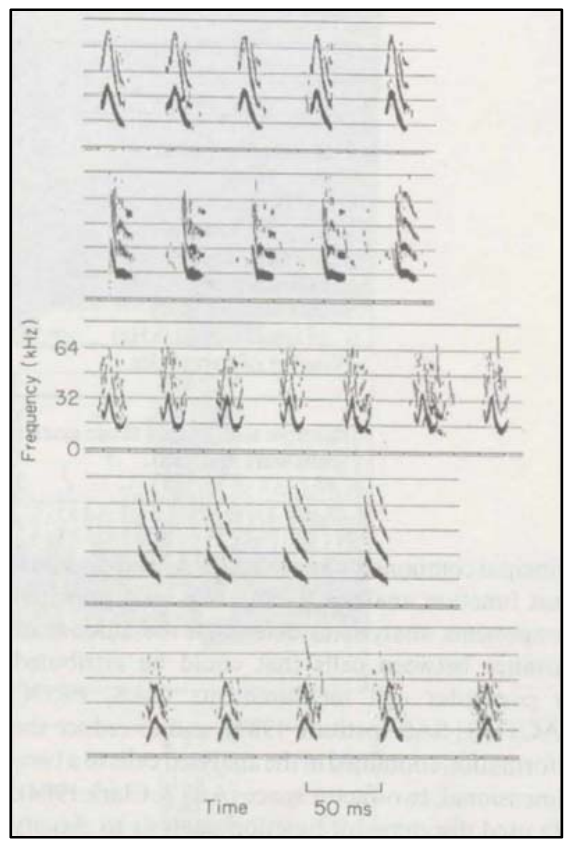

Figure 2. Directive calls from each of five different mother bats recorded inside James River Cave. 
With few exceptions, pulses in a call were similar. Each pulse was a distinct tonal unit, usually with one or more frequency modulations. Some calls contained pulses with a single (usually downward) sweep, while others contained pulses with up to three consecutive modulations. The intensity of directive calls was very high and could be detected over background noise within the roost (Fig. 3).

Table 1. Characteristics of T. b. mexicana directive calls.

\begin{tabular}{|l|c|c|c|}
\hline Call Feature & $\overline{\boldsymbol{X}} \pm \boldsymbol{S} \boldsymbol{\text { Range }}$ & $\mathbf{N}^{*}$ \\
\hline Call duration (ms) & $350 \cdot 0 \pm 4 \cdot 8$ & $137 \cdot 5-1297 \cdot 3$ & 151 \\
\hline Pulses per call & $5 \cdot 6 \pm 0 \cdot 2$ & $2-18$ & 151 \\
\hline Pulse duration (ms) & $21 \cdot 0 \pm 0 \cdot 1$ & $13 \cdot 9-31 \cdot 3$ & 377 \\
\hline Inter-pulse interval (ms) & $50 \cdot 9 \pm 0 \cdot 9$ & $24 \cdot 4-111 \cdot 6$ & 360 \\
\hline Maximum frequency of fundamental $(\mathrm{kHz})$ & $38 \cdot 9 \pm 0 \cdot 5$ & $14 \cdot 4-60 \cdot 8$ & 378 \\
\hline Minimum frequency of fundamental $(\mathrm{kHz})$ & $10 \cdot 8 \pm 0 \cdot 2$ & $6 \cdot 4-30 \cdot 7$ & 378 \\
\hline Number of harmonics & $3 \cdot 8 \pm 0 \cdot 1$ & $1-11$ & 372 \\
\hline
\end{tabular}

*Sample sized exceed those given in Methods where additional recorded calls were analysed.

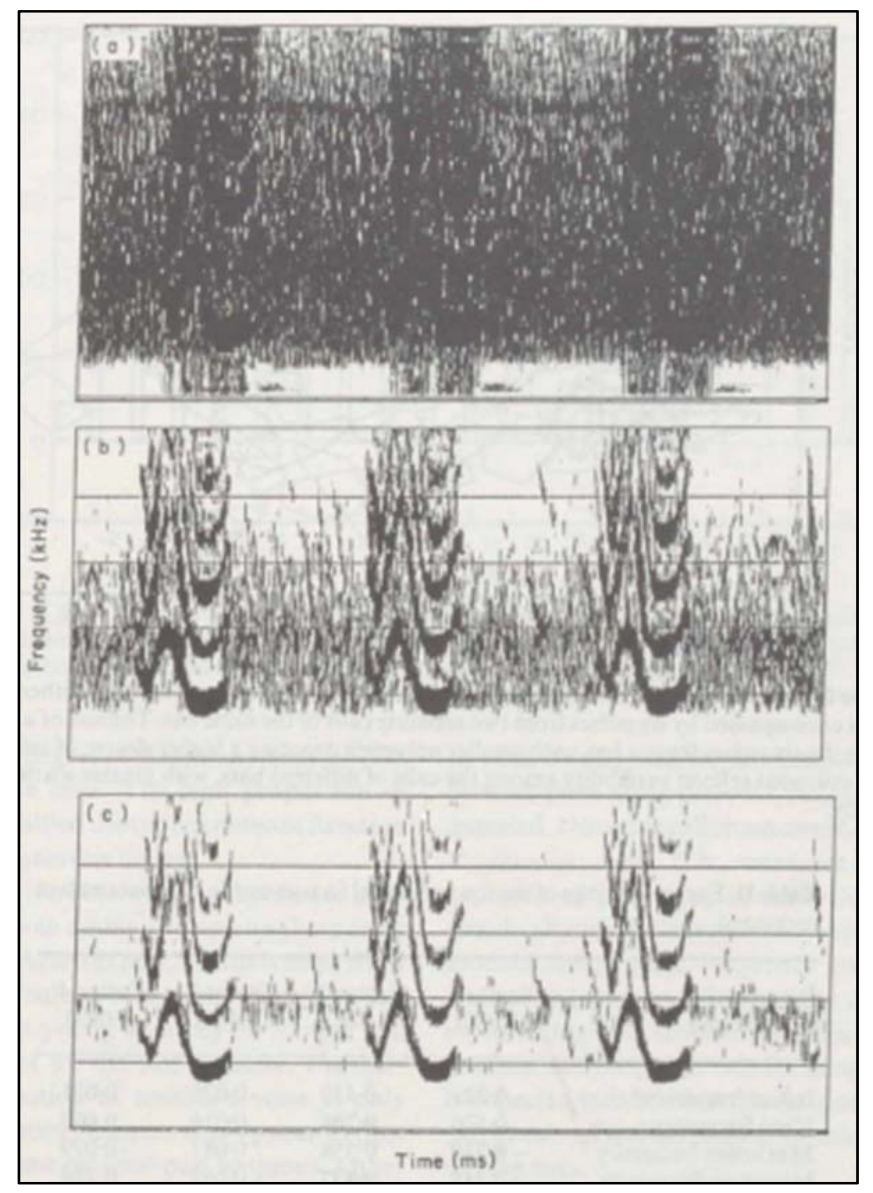

Figure 3. Three sonagrams from the same segment of a mother directive call recording made inside the cave, illustrating the high intensity of directive calls relative to other sounds inside the cave. The traces were generated by varying the background sound input setting on the MacSpeech Lab II computer program. The highest input setting shown (a) displays much of the lower intensity sound on the recording; successively lower settings (band c) eliminate more of the background noise, leaving only the most intense sounds, in this case, directive call pulses. 


\section{Distinctiveness of Directive Calls}

There was both considerable stereotypy between pulses within directive calls, and considerable variability between pulse from different bats (Figs 2, 4). Principal components factors 1 and 2 accounted for 27 and 19\% of the total variability in call measurements, respectively. The first four factors exceeded the mineigen criterion (eigenvalue $>1 \cdot 0$, SAS Institute 1989). Initial call frequency, the number of inversions (i.e. number of consecutive frequency modulations within a pulse; see Fig. 1) and maximum frequency loaded most heavily in the first factor; minimum call frequency and final frequency loaded highest in the second factor (Table 2).

The data for all nine call variables used in this analysis were non-normally distributed (PROC UNIVARIATE; SAS Institute 1989). However, use of the cross-validation technique in the discriminant function analysis revealed that these deviations from normality did not reduce the discriminability of the call (Afifi \& Clark 1984). The analysis correctly assigned 279 of the 300 pulses to the mother bat $(N=50)$ who produced them. In the comparison of mother directive with pup isolation calls, each call type was found to be equally discriminable, with 96 and $97 \%$ correct classification, respectively.

\section{Playbacks}

Of the 20 pups tested, 19 had positive difference scores (Fig. 5), thus showing apparent preference for the model placed in front of a directive call stimulus. Average $( \pm S E) T_{1}$ was $258 \cdot 3 \pm 24 \cdot 2 \mathrm{~s}$; average $\mathrm{T}_{2}$ was $56 \cdot 4 \pm 11 \cdot 2 \mathrm{~s}(\mathrm{P}<0 \cdot 0001)$.

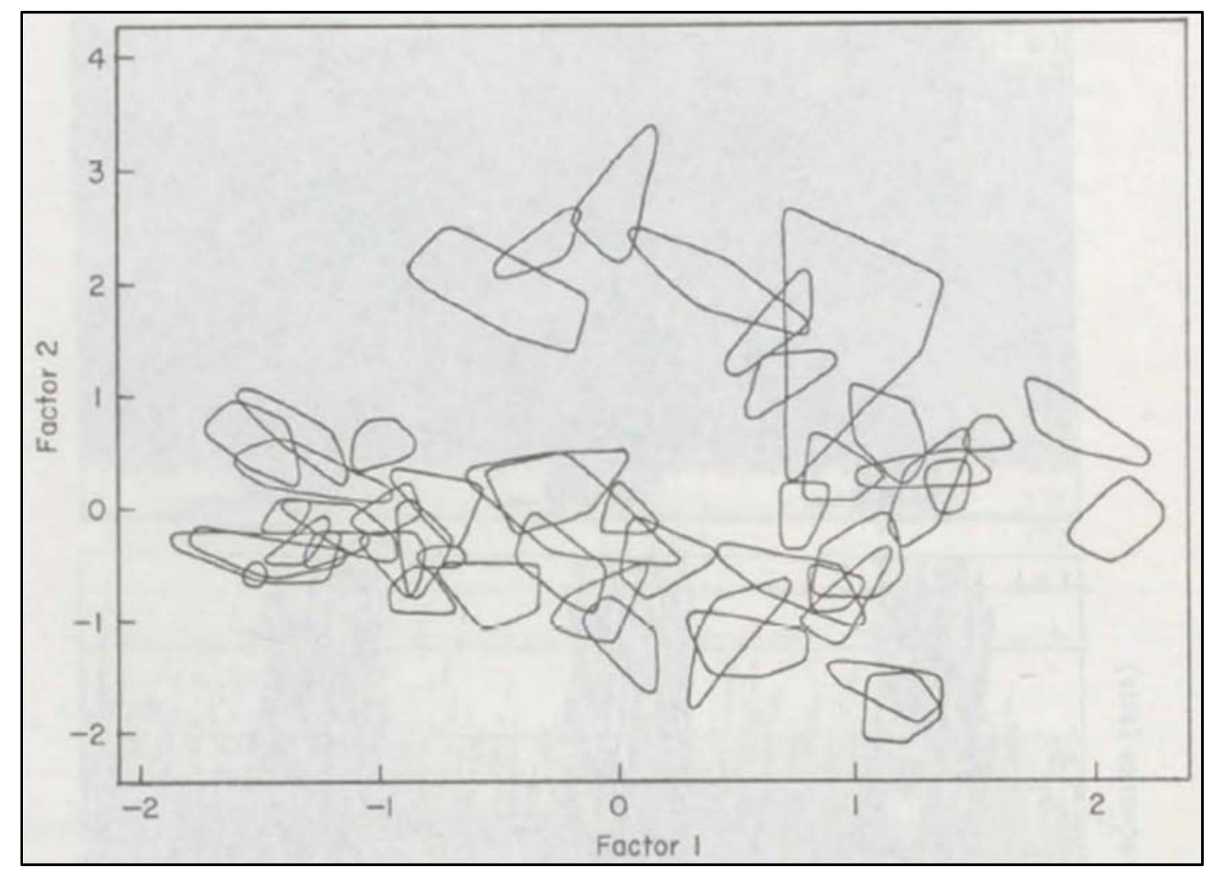

Figure 4. Plot of the first two factors in principal components analysis of directive calls of 50 mother bats. Each polygon represents the area encompassed by six pulses from two separate calls of the same bat. The size of a polygon reflects the similarity amongst the six pulses from a bat, with smaller polygons denoting a higher degree of inter-pulse stereotypy. The scatter of the polygons reflects variability among the calls of different bats, with greater scatter denoting a higher degree of variability. 
Table 2. Factor loadings of the four principal factors on the nine parameters measured

\begin{tabular}{|l|c|c|c|c|}
\hline $\begin{array}{c}\text { Parameter } \\
\text { (eigenvalue) }\end{array}$ & $\begin{array}{c}\text { Factor 1 } \\
\mathbf{( 2 . 5 8 5 )}\end{array}$ & $\begin{array}{c}\text { Factor 2 } \\
\mathbf{( 1 . 8 8 8 )}\end{array}$ & $\begin{array}{c}\text { Factor 3 } \\
(\mathbf{1 . 4 9 0 )}\end{array}$ & $\begin{array}{c}\text { Factor 4 } \\
(\mathbf{1 . 0 0 1})\end{array}$ \\
\hline Initial frequency* & $-\mathbf{- 0 . 8 2 1}$ & 0.439 & --0.076 & 0.031 \\
\hline Final frequency & 0.576 & $\mathbf{0 . 7 0 8}$ & 0.016 & 0.060 \\
\hline Maximum frequency & $--\mathbf{0 . 7 1 8}$ & 0.558 & 0.087 & --0.079 \\
\hline Minimum frequency & 0.316 & $\mathbf{0 . 8 3 7}$ & --0.062 & 0.264 \\
\hline Frequency of maximum energy & --0.011 & 0.198 & $\mathbf{0 . 8 4 8}$ & 0.120 \\
\hline Number of harmonies & --0.096 & 0.004 & $\mathbf{0 . 7 0 4}$ & --0.591 \\
\hline Number of inversions & $\mathbf{0 . 7 4 4}$ & 0.172 & 0.112 & --0.151 \\
\hline Pulse duration & 0.630 & --0.093 & 0.057 & --0.070 \\
\hline Inter-pulse duration & --0.066 & --0.323 & 0.493 & $\mathbf{0 . 7 2 8}$ \\
\hline
\end{tabular}

Those parameters that loaded highest in each factor are shown in bold type.

*Frequency measures refer to the fundamental frequency only.

\section{DISCUSSION}

Acoustic signals that function for individual recognition and facilitate the reunions of individuals should be detectable and discriminable. Our results show that the directive calls of adult T. b. mexicana possess these characteristics. Delectability requires that the signal be audible above other nearby sounds. Figure 3 illustrates that, while noise levels are very high in these roosts, directive calls are intense and detectable above this noise at a distance of at least $1 \mathrm{~m}$. Because mother T. b. mexicana typically land on the creche within $1 \mathrm{~m}$ of their pup ( $X=0.45 \mathrm{~m}$; McCracken \& Gustin, in press), this range of delectability is apparently adequate for reunion purposes. Discriminable signals should show high stereotypy within individuals and detectable differences among different individuals. These features are expected of vocal signals evolved for individual recognition (Falls 1982). Figures 2 and 5 illustrate the high degree of discriminability of T. b. mexicana directive calls. The high proportion of calls correctly classified using discriminant function analysis corroborates this finding.

That some calls were incorrectly classified to individual suggests some ambiguity among these calls. However, we should not expect our analyses to show different mothers' calls to be completely unique. It is quite possible that young bats key on mother call characteristics that we did not measure. Furthermore, pup recognition of mother's voice is only one of everal sensory element that appear to promote T. b. mexicana mother-pup reunions. Other studies in our laboratory have explored the role of pup vocalizations (Gelfand \& McCracken 1986; Balcombe 1990), olfactory recognition (Gustin \& McCracken 1987; Loughry \& McCracken, in press) and locational memory (McCracken \& Gustin, in press) in effecting these reunions.

The directive calls of mothers have been described for two other bat species of different families: Antrozous pallidus (Vespertilionidae; Brown 1976), and Phyllostomus discolor (Phyllo tomidae; Esser \& Schmidt 1989). In each of these studies, the authors describe call characteristics and suggest behavioural functions similar to those of our study. Brown (1976) observed A. pallidus mothers uttering directive calls in response to their infants' isolation calls. Esser \& Schmidt (1989) describe the directives of mother P. discolor as representing vocal signatures based on distinctive frequency-time structure. In both studies, 
individual recognition of mothers by their pups using directive calls is suggested, but untested. Directive call characteristics of A. pallidus, P. discolor, and T. b. mexicana share features expected of calls used in individual recognition, specifically: loud, clear notes with repeated pulses or modulations, broad frequency modulation, and multiple harmonics. The findings of these studies, representing bats from three different chiropteran families, and the gregarious roosting habits of many bat species, indicate that directive calls and reciprocal parent-offspring recognition may be widespread among bats.

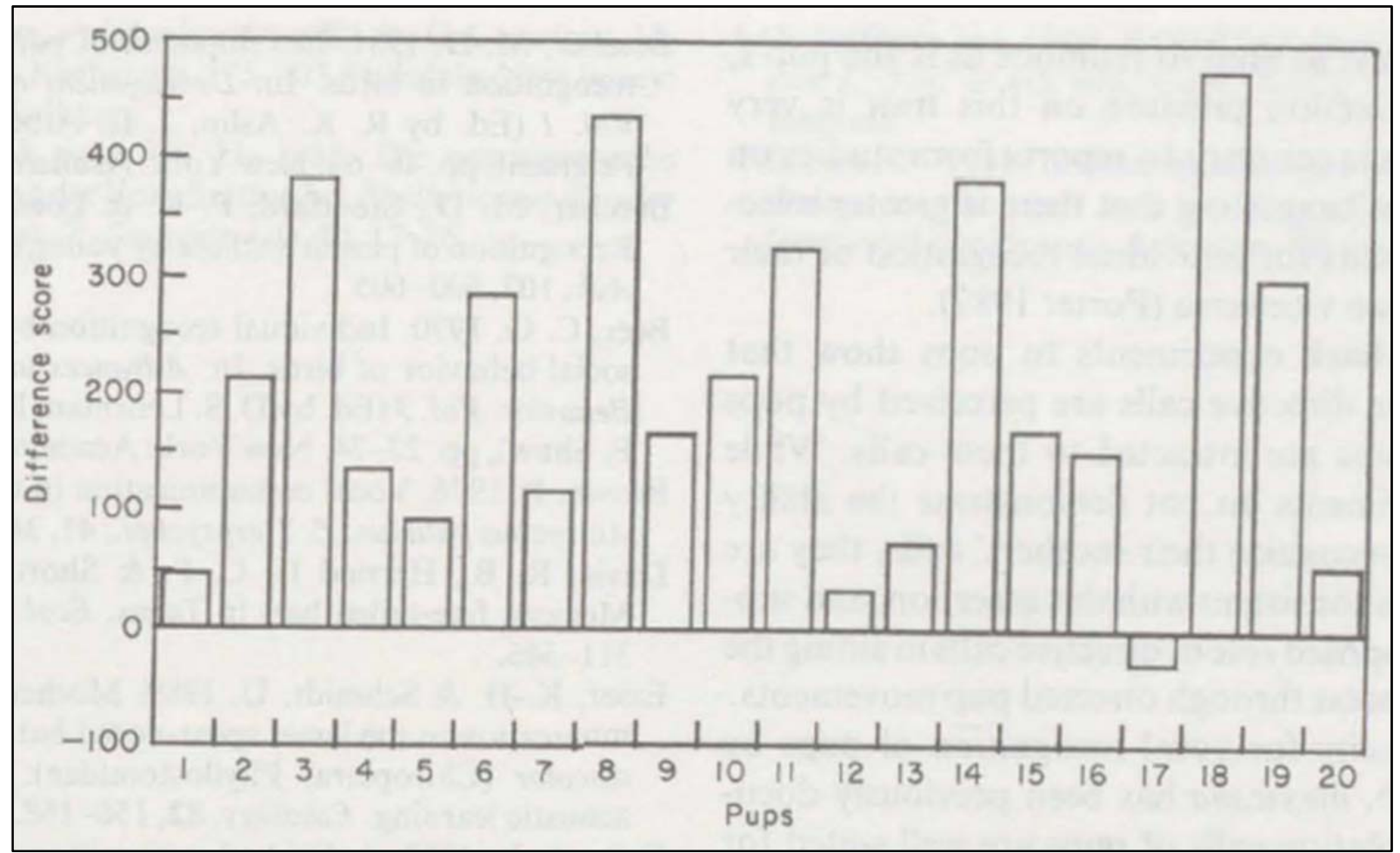

Figure 5. Responses of pups to directive call playbacks. Each bar represents the response of one of the 20 pups tested. The ordinate scale represents time in seconds. Bars above the horizontal line reflect preference of a pup for the directive call stimulus. See Methods (Statistical Procedures) for explanation of the difference score.

Our findings suggest that successful reunions are facilitated by the ability of T. b. mexicana pup to recognize their mother's calls. Pup recognition of their mothers could be beneficial by (I) prompting movements of pups towards their mothers, and (2) stimulating pups to call when they hear their mother's voice, thereby directing the mother towards the pup. In all of the in-cave reunion videos of marked mothers and pups mapped by McCracken \& Gustin (in press), pup moved toward their presumptive mothers ( $X=10 \cdot 4$, range $5 \cdot 6-17 \cdot 3 \mathrm{~cm}$ ), and in one reunion the pup moved further than did the mother. These observations provide additional evidence that a pup recognizes its mother's voice, and that this recognition ability facilitates reunions. The analyses showing that mother directive calls are as statistically discriminable as pup isolation calls suggest that the parent's vocalization is as vital to reunions as is the pup's, and that selection pressure on this trait is very strong. This is contrary to reports from studies on other species suggesting that there is greater selection on parents for individual recognition of their offspring than vice versa (Porter 1987). 
Our playback experiments to pups show that adult female directive calls are perceived by pups and that pups are attracted to these calls. While these experiments do not demonstrate the ability of pups to recognize their mothers' calls, they are nevertheless consistent with this assertion, and support the proposed role of directive calls in aiding the reunion process through directed pup movements.

The capacity for vocal recognition of pups by mother T. b. mexicana has been previously documented. Isolation calls of pups are well suited for individual recognition (Gelfand \& McCracken 1986), and mothers prefer the calls of their own pups over those of strange pups in two-way choice playback presentations (Balcombe 1990). Thus, we know that at some stage in their ontogeny these bats develop the ability to discriminate among the vocalizations of different individuals. Given the benefits to both infants and parents of a pup recognizing its mother's voice, and the evidence we present in this paper, this ability apparently develops early in life.

\section{ACKNOWLEDGMENTS}

We are grateful to M. B. Fenton for long-term loans of Racal tape recorders, to C. R. B. Boake for use of sound analysis equipment, and to G. D. Pollak for loaning us tape recorder accessories. Stephen Killeffer, Stan Guffey, Donna Hensley and Spider Johnson provided valuable field assistance, and Clinton and Anne Schultze graciously permitted us access to James River Cave. We also thank Michael Beecher, John Hayes, Jianming Shen and two anonymous referees for comments on earlier drafts of the manuscript. This research was supported by an Animal Behavior Society Research Grant and a University of Tennessee Ethology Research Grant to J.P.B., and NSF Grant BSR-8700425 to G.F.M.

\section{REFERENCES}

Afi.fi, A. A. \& Clark, V. 1984. Computer-aided Multivariate Analysis. London: Lifetime Learning Publications.

Balcombe, J. P. 1990. Vocal recognition of pups by mother Mexican free-tailed bats, Tadarida brasiliensis mexicana. Anim. Behav., 39, 960-966.

Beecher, M. D. 1981. Development of parent-offspring recognition in birds. In: Development of Perception. Vol. I (Ed. by R. K. Aslin, J. R. Alberts \& M. R. Petersen), pp. 46-66. New York: Academic Press.

Beecher, M. D., Stoddard, P. K. \& Loesche, P. 1985. Recognition of parent's voices by young cliff swallows. Auk, 102, 600-605.

Beer, C. G. 1970. Individual recognition by voice in the social behavior of birds. In: Advances in the Study of Behavior. Vol. 3 (Ed. by D. S. Lehrman, R. A. Hinde \& E. Shaw), pp. 27-74. New York: Academic Press.

Brown, P. 1976. Vocal communication in the pallid bat, Antrozous pallidus. Z. Tierpsychol., 41, 34-54. 
Davis, R. B., Herried II, C. F. \& Short H. L. 1962. Mexican free-tailed bat in Texas. Ecol. Monogr., 32, 311-346.

Esser, K.H. \& Schmidt, U. 1989. Mother infant communication in the lesser spear-nosed bat Phyllostomus discolor (Chiroptera, Phyllostomidae): evidence for acoustic learning. Ethology, 82, 156168.

Falls, J. B. 1982. Individual recognition by sounds in birds. In: Acoustic Communication in Birds. Vol. 2 (Ed. by D. E. Kroodsma \& E. H. Miller), pp. 237-278. New York: Academic Press.

Gelfand, D. L. \&McCracken, G. F. 1986. Individual variation in the isolation calls of Mexican free-tailed bat pups, Tadarida brasiliensis mexicana. Anim. Behav., 34, 1078-1086.

Gustin, M. K. \& McCracken, G. F. 1987. Scent recognition $m$ the Mexican free-tailed bat, Tadarida brasiliensis mexicana. Anim. Behav., 35, 13-19.

Hand, D. J. 1981. Discrimination and Classification. New York: John Wiley.

Holmes, W. G. 1990. Parent-offspring recognition in mammals: a proximate and ultimate perspective. In: Mammalian Parenting: Biochemical, Neurobiological, and Behavioral Determinants (Ed. by . A. Krasnegor \& R. S. Bridges), pp. 440-460. New York: Oxford University Press.

Jones, I. L., Falls, J. B. \& Gaston, A. J. 1987. Vocal recognition between parent and young of ancient murrelets, Syntlzliboramphus antiquus (Aves: Alcidae). Anim. Behav., 35, 14051415.

Loughry, W. J. \& McCracken, G. F. 1991. Factors influencing female-pup scent recognition in Mexican free-tailed bats. J. Mammal., 72, 624-626.

McArthur, P. D. 1982. Mechanisms and development of parent-young recognition in the piñyon jay (Gymnorhinus cyanocephalus). Anim. Behav., 30, 62-74.

McCracken, G. F. 1984. Communal nursing in Mexican free-tailed bats. Science, 223, 10901091.

McCracken, G. F. \& Gu tin, M. K. In press. Nursing behavior in Mexican free-tailed bat maternity colonies. Ethology.

Mistry, S. \& McCracken, G. F. 1990. Behavioural response of the Mexican free-tailed bat, Tadarida brasiliensis mexicana, to visible and infrared light. Anim. Behav., 39, 598-599.

Pierotti, R. \& Murphy, E. C. 1987. Intergeneration conflicts in gulls. Anim. Behav., 35, 435 444.

Porter, R. H. 1987. Kin recognition: functions and mediating mechanisms. In: Sociobiology and Psychology Ideas.Issues, and Applications (Ed. by C. Crawford, M. Smith \& D. Krebs), pp. 175 203. Hill dale, New Jersey: Lawrence Erlbaum. 
Rother, G. \& Schmidt, U. 1985. Die ontogenetische Entwicklung der Vokalisation bei Phyllostomusdiscolor (Chiroptera). Z. Siiugetierkde, 50, 17-26.

SAS Institute Inc. 1989. SAS:STAT User's Gwde, Version 6. Vol. 1. 4th edn. Cary, North Carolina: SAS Institute.

Trillmich, F. 1981. Mutual mother-pup recognition in Galapagos fur seals and sea lions: Cues used and functional significance. Behaviour, 78, 21-42. 